\title{
Thomas de Kent, Le Roman d'Alexandre ou le Roman de toute chevalerie
}

\section{Barbara Ferrari}

\section{(2) OpenEdition}

12 Journals

\section{Édition électronique}

URL : https://journals.openedition.org/studifrancesi/37157

DOI : 10.4000/studifrancesi.37157

ISSN : 2421-5856

Éditeur

Rosenberg \& Sellier

\section{Édition imprimée}

Date de publication : 15 décembre 2004

Pagination : 578

ISSN : 0039-2944

\section{Référence électronique}

Barbara Ferrari, "Thomas de Kent, Le Roman d'Alexandre ou le Roman de toute chevalerie », Studi

Francesi [En ligne], 144 (XLVIII | III) | 2004, mis en ligne le 30 novembre 2015, consulté le 08 mai 2021.

URL : http://journals.openedition.org/studifrancesi/37157 ; DOI : https://doi.org/10.4000/

studifrancesi.37157

Ce document a été généré automatiquement le 8 mai 2021.

\section{(c)}

Studi Francesi è distribuita con Licenza Creative Commons Attribuzione - Non commerciale - Non opere derivate 4.0 Internazionale. 


\title{
Thomas de Kent, Le Roman d'Alexandre ou le Roman de toute chevalerie
}

\author{
Barbara Ferrari
}

\section{RÉFÉRENCE}

THOMAS DE KENT, Le Roman d'Alexandre ou le Roman de toute chevalerie, traduction, présentation et notes de CATHERINE GAULLIER-BOUGASSAS et LAURENCE HARF-LANCNER, avec le texte édité par BRIAN FOSTER et IAN SHORT, Paris, Champion (Champion Classiques «Moyen Age», 5) 2003, $743 \mathrm{p}$.

1 L'Alexandre anglo-normand de Thomas de Kent n'a pas connu un succès comparable à celui du roman d'Alexandre de Paris ou de l'adaptation en prose de l'Historia de Preliis; rédigé entre 1175 et 1185 en laisses d'alexandrins, il est conservé uniquement dans trois manuscrits complets et deux fragments du deuxième quart du XIII ${ }^{\mathrm{e}}$ siècle et de la première moitié $\mathrm{du} \mathrm{XIV}^{\mathrm{e}}$, et sa circulation a été vraisemblablement limitée aux territoires insulaires. A la différence de son contemporain Alexandre de Paris, qui a réuni et adapté des récits français précédents, Thomas de Kent a travaillé directement sur les sources latines et a donc le mérite d'avoir «créé seul, selon toute vraisemblance, une version nouvelle en français» (p. XI).

2 La riche «Introduction» (pp. VII-LXXII) permet d'aborder le texte avec toutes les informations nécessaires: Ch. G.-B. et L. H.-L présentent les hypothèses concernant l'auteur (dont on ne sait presque rien mais dont la culture révèle l'appartenance au milieu des clercs), et son public (vraisemblablement la cour d'Henri II Plantagenêt). Elles mettent en rapport ensuite le Roman de toute chevalerie avec les autres Romans d'Alexandre du XII ${ }^{\mathrm{e}}$ siècle, en soulignant les écarts qui séparent cette version de la vulgate continentale. L'analyse littéraire du poème, très articulée, approfondit notamment: la «mise en scène de l'auteur dans son texte» ( $\mathrm{p}$. XX), l'un des aspects 
novateur de cet ouvrage; le caractère hybride de son statut générique, entre chanson de geste et romanz; l'image du héros, 'réinventée' par l'auteur malgré les contraintes des sources historiques.

3 Les pp. LXVI-LXVIII sont consacrées à la présentation de la tradition manuscrite et des problèmes éditoriaux qu'elle pose. Suivent l'analyse du récit (pp. LXIX-LXXII) et une ample bibliographie. L'édition Foster-Short reproduite ici (publiée par l'Anglo-Norman Text Society en 1976 et 1977), est accompagnée, comme c'est l'usage de la collection, de notes et d'une traduction originale (pp. 1-641). L'«Apparat des variantes» (pp. 643-699) est suivi d'un «Glossaire» sélectif (pp. 701-727) et d'un «Index des noms propres» (pp. 729-741). 